\title{
Maternal and perinatal outcome of Evan's syndrome: a 5 years study in a tertiary care centre
}

\author{
Manjula S. K., Jasmine Deva Arul Selvi T., Vishnu Priya K. M. N.*
}

Department of Obstetrics and Gynecology, St. John's Medical College Hospital, Bangalore, Karnataka, India

Received: 24 March 2019

Accepted: 04 May 2019

\section{*Correspondence:}

Dr. Vishnu Priya K. M. N.,

E-mail: kmn_priyanil@yahoo.co.in

Copyright: () the author(s), publisher and licensee Medip Academy. This is an open-access article distributed under the terms of the Creative Commons Attribution Non-Commercial License, which permits unrestricted non-commercial use, distribution, and reproduction in any medium, provided the original work is properly cited.

\begin{abstract}
Background: Evans syndrome is a rare autoimmune disorder characterized by simultaneous or sequential presence of a positive antiglobulin test, autoimmune haemolytic anemia (AIHA), and immune thrombocytopenia (ITP). It is characterised by frequent exacerbations and remissions within a chronic course. It was first described by Robert Evans in 1951. Incidence of AIHA is 1 per $75-80,000$ and ITP is 5.5 /100000 per general adult population. Incidence of Evans syndrome is $1.8 \%$ to $10 \%$ of patients with ITP. Objective was to study the maternal and perinatal outcome of women with Evans syndrome (E).

Methods: About 4 antenatal mothers were identified with Evans syndrome at St. Johns medical college and hospital, Bengaluru during the study period of 5 years from July 2013-July 2017. They were followed up during their antenatal, intra natal and postnatal period and outcomes were studied. All patients included in the study fulfilled the criteria for Evans syndrome.

Results: There were 4 cases of Evans syndrome, with a total number of deliveries of 11859, during this 5 year study. Incidence was 0.09 per 1000 births. All patients presented with bleeding manifestations ranging from mucosal haemorrhage to subarachnoid haemorrhage $(\mathrm{SAH})$ at the time of diagnosis. All patients were on treatment with either $1^{\text {st }}$ or $2^{\text {nd }}$ line of management with corticosteroids/ azathioprine. None had bleeding during pregnancy after the initiation of treatment. Patients had antenatal complications like preeclampsia 25\%, IUGR 25\%, oligohydraminos $50 \%$, IUD $25 \%$. 2 patients received platelet transfusions intrapartum. None had intrapartum or postpartum haemorrhage. There were no maternal and neonatal mortality.

Conclusions: Evans syndrome in pregnancy is a rare condition and requires multi disciplinary approach involving specialists from obstetrics, neonatology, and hematology. Close maternal and fetal surveillance and management during pregnancy is essential to increase the possibility of a favourable pregnancy outcome in these women.
\end{abstract}

Keywords: Autoimmune thrombocytopenia, Autoimmune haemolytic anaemia, Azathioprine, corticosteroids, Evans syndrome, IVIG

\section{INTRODUCTION}

Evans syndrome is a rare autoimmune disorder characterized by simultaneous or sequential presence of a positive antiglobulin test, autoimmune haemolytic anemia (AIHA), and immune thrombocytopenia (ITP). It is characterised by frequent exacerbations and remissions within a chronic course. It was first described by Robert
Evans in 1951. Incidence of AIHA is 1 per 75 - 80,000 and ITP is 5.5/100000 per general adult population1. Incidence of Evans syndrome is $1.8 \%$ to $10 \%$ of patients with ITP. ${ }^{2}$ This syndrome can be classified as primary or idiopathic, and secondary when associated with conditions such as systemic lupus erythematosus (SLE), lymphoproliferative disorders or primary immunodeficiencies, Sjogren syndrome, IgA deficiency, 
primary antiphospholipid syndrome, Hodgkin's disease. In childhood, ES may also show an autoimmune lymphoproliferative syndrome (ALPS), a disorder of disrupted lymphocyte homeostasis related to some mutations in the Fas apoptotic pathway. It is mainly a diagnosis of exclusion characterised by decreasing levels of IgM, IgG and $\operatorname{IgA}$.

Evans syndrome presents in both children and adults. In adults it is common in women (2:1 ratio). It presents with bicytopenia which can coincide or occur separately or sequentially. After the appearance of the first cytopenia, the second may occur months to years later which can delay the diagnosis. In Evan's syndrome, ITP is due to the auto antibodies ( $\mathrm{IgG})$ against glycoproteins on platelet surfaces especially Ib/IX, IIb/IIIa causing premature destruction by reticuloendothelial system. In AIHA autoantibody (IgG) is warm type, hemolysis occurring extra-vascularly in spleen between $35-40^{\circ} \mathrm{C}$.

Diagnosis of Evans syndrome is by decreased levels of serum immunoglobulin, positive direct Coombs test. As Evans syndrome is a diagnosis of exclusion, other confounding factors have to be ruled out by performing different tests such as ELISA for HIV I and II, malarial antigen, urine examination, ultrasonography, chest X-ray, antinuclear antibody and Ham's test, ANA and dsDNA (to rule out SLE). ${ }^{3}$ Bone marrow examination if the patient is presenting with pancytopenia to exclude infiltrative process or an aplastic marrow.

First line treatment for Evans syndrome is corticosteroids with or without intravenous immunoglobulins (IVIG). ${ }^{4}$ Second line of management includes immunosuppressive agents, the monoclonal antibody rituximab, chemotherapy or combination of these. Only a small percentage had complete remission and also these drugs have numerous adverse effects. Splenectomy may also be considered as second line management. ${ }^{5}$ For patients with relapses with first and second line therapy, the third line of management includes cyclophosphamide, alemtuzumab or stem cell transplantation. ${ }^{6}$

\section{METHODS}

In this retrospective observational study conducted at St. John's medical college and hospital, from 2013 - 2018, pregnant women diagnosed with Evans syndrome were observed for antenatal, intranatal, postnatal complications, response to treatment, neonatal outcomes. The patients were given multi speciality care by team including - obstetrician, hematologists, neonatologist.

\section{Inclusion criteria}

- The antenatal mothers with ES defined as the simultaneous (within 1 month) or sequential (within at most a 10-year period of time) association of ITP and AIHA were included in study
- ITP was defined according to American Society of Hematologycriteria, platelet count below 1,00,000 cell/ $\mathrm{mm}^{3}$ on 2 separate occasions were included ${ }^{7}$

- $\quad$ AIHA was defined by an Hb level $<11 \mathrm{~g} / \mathrm{dL}$ with a positive direct antiglobulin test (DAT) and at least one hemolysis criteria among the following: reticulocytosis $>1,00,000 / \mathrm{dL}$, total bilirubin $>1.2$ $\mathrm{mg} / \mathrm{dL}$, and haptoglobin $<10 \mathrm{mg} / \mathrm{dL}$.

\section{Exclusion criteria}

- Patients with isolated DAT and/or compensated hemolysis without anemia or patients with antiplatelet antibodies without thrombocytopenia were not considered to have ES

Data on maternal age, obstetric history, age of onset, drug used, response to treatment, course in pregnancy, associated pregnancy complications, gesational age at delivery, neonatal outcomes, and postnatal complications were collected.

\section{Statistical definitions}

Severity of AIHA and ITP at initial diagnosis:

ITP severity score defined by the Buchanan's score scale of 0 (none) to 5 (life-threatening or fatal), mucosal hemorrhages defined a grade of 3 (moderate). ${ }^{7}$

\section{AIHA cerevance score}

- $\quad$ grade 0: no sign of anemia

- $\quad$ grade 1: pallor, fatigue, no impact on daily life

- grade 2: tachycardia, malaise, dizziness, significant impact on daily life

- grade 3: cardiac, renal, or neurological impairment.

\section{Primary and secondary $\mathrm{ES}$}

In primary ES cases, no immune manifestations could be identified during the entire follow-up. Secondary ES cases were associated with a primary genetically identified immunodeficiency (PID) or SLE.

To asses response to treatment - for AIHA, a complete response (CR) was defined by a $\mathrm{Hb}$ level of $12 \mathrm{~g} / \mathrm{dL}$ or more in the absence of any transfusion without features of hemolysis. A partial response (PR) was defined by a $\mathrm{Hb}$ level of at least $10 \mathrm{~g} / \mathrm{dL}$ with an increase of at least 2 $\mathrm{g}$ from baseline and a persistent hemolysis. For ITP, a CR was defined by a normal platelet count (ie, > 1,50,000 cells $/ \mathrm{mm}^{3}$ ) and a PR by a platelet count greater than 50,000 cells $/ \mathrm{mm}^{3}$ with at least a 2 -fold increase of the pretreatment count. ${ }^{8}$

Management protocol included drugs like steroids, IVIG as per haematologists advise. Anticipation of pregnancy complications like preeclampsia, IUGR. Antenatal 
steroids were considered if indicated. Fetal surveillance by non stress test, biophysical profile, obstetric ultrasound, doppler, daily fetal movement counts. Supportive management during labour includes transfusions of blood and blood products.

\section{RESULTS}

During the period of 5 years, 4 cases of Evans syndrome were identified among women who delivered during this period. Incidence of Evan syndrome was 0.09 per 1000 births in our study. The demographic details and clinical features of cases are shown in Table 1. Age of the patients ranged between 23 and 34 years with a mean of 27.5 years. Out of four patients one was primi three were multi, of which one patient was diagnosed with Evans syndrome during pregnancy at 26 weeks of gestation. Mean age of diagnosis is 25.5 years. Bleeding manifestations ranged from mucosal bleeds to $\mathrm{SAH}$.
Severity score for ITP at the time of diagnosis ranged from 3-5 (moderate to severe), for AIHA from 1-2.

All four patients were managed with high dose intravenous steroids at the time of diagnosis which were changed to oral medications later on. 3 patients were on combination of 1st and 2nd line therapy (corticosteroids + azathioprine) prior to pregnancy whereas only 1 patient continued both, 2 patients took only steroids and one patient was advised only azathioprine during pregnancy. Compliance to treatment was $100 \%$. All patients responded to treatment and were asymptomatic during pregnancy. 3 patients required platelet transfusions at the time of diagnosis, with a mean platelet transfusion of 7.6 pints. One patient required 4 pint packed cells transfusions. None of the patients required any transfusions during pregnancy (except for the one patient who was diagnosed to have Evans syndrome during pregnancy).

Table 1: Demographic and clinical details of pregnant women with Evans syndrome.

\begin{tabular}{|c|c|c|c|c|c|c|c|}
\hline Age & Ob score & $\begin{array}{l}\text { Age at } \\
\text { diagnosis }\end{array}$ & $\begin{array}{l}\text { GA at } \\
\text { delivery }\end{array}$ & $\begin{array}{l}\text { ITP-severity } \\
\text { score at diagnosis }\end{array}$ & $\begin{array}{l}\text { AIHA-severity } \\
\text { score }\end{array}$ & Drugs & $\begin{array}{l}\text { Transfusion prior } \\
\text { to pregnancy }\end{array}$ \\
\hline 28 & G2A1 & 27 & $33+4$ & 4 & 1 & $\mathrm{~W}+\mathrm{A}$ & 5 platelet \\
\hline 23 & G4P3L3 & $23(26 \mathrm{wks})$ & $38+6$ & 5 & 2 & $\mathrm{~W}$ & 8 platelet $+4 \mathrm{PC}$ \\
\hline 34 & Primi & 33 & $26+1$ & 3 & 1 & $\mathrm{~W}+\mathrm{A}$ & \\
\hline 25 & G3P1L1A1 & 19 & $39+2$ & 3 & 1 & $\mathrm{~W}+\mathrm{A}$ & 10 platelet \\
\hline
\end{tabular}

W -Wysolone, A-Azoran.

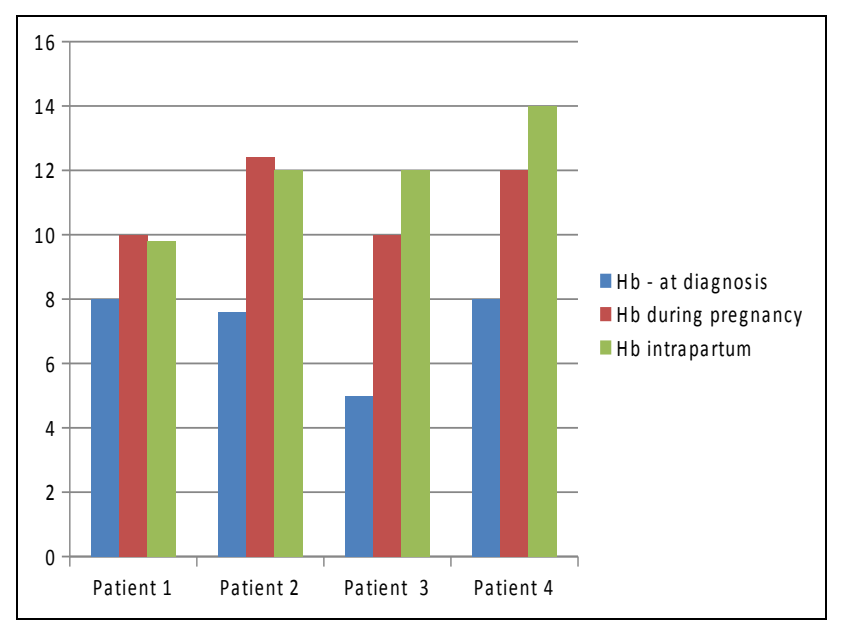

Figure 1: Hemoglobin levels.

Hemoglobin at the time of diagnosis ranged from 5$8 \mathrm{gm} / \mathrm{dL}$ with a mean of $7.1 \mathrm{gm} / \mathrm{dL}$. Platelet count ranged between 26,000 to 80 , 000 with a mean of 44,750. The mean Hemoglobin and platelet counts during pregnancy were $11.1 \mathrm{gm} / \mathrm{d} \mathrm{L}$ and 70,750. Mean haemoglobin and platelet count in the intrapartum period was in range of $11.9 \mathrm{gm} / \mathrm{d} \mathrm{L}$ and 74,750 Figure 1, 2. None had neutropenia.

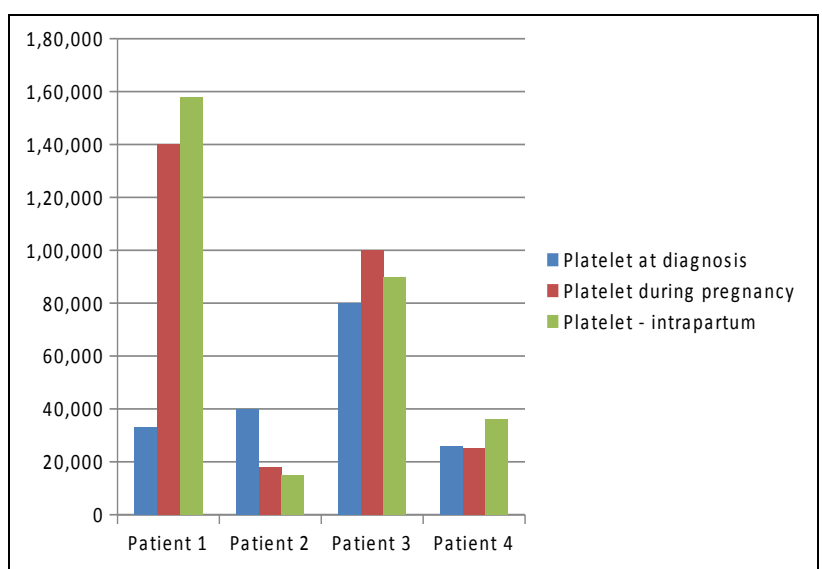

Figure 2: Platelet counts.

Antenatal complications included Preeclampsia (25\%), Asymmetrical intra uterine growth restriction (IUGR) (25\%), Oligohydraminos (50\%), Doppler changes $(25 \%)$, Intra uterine demise (IUD) (25\%). Figure 3. During postpartum period 1 patient had pyelonephritis (25\%) treated with antibiotics, one patient had puerperal pyrexia. Intrapartum none had any complications. Mean duration of hospital stay was 8 days. 3 (75\%) women delivered by vaginal delivery and 1 underwent 
emergency lower segment caesarean section (LSCS) in view of fetal distress. $50 \%$ delivered at term and $50 \%$ preterm deliveries included one IUD, and for fetal distress. 2 patients $(50 \%)$ received high dose intravenous steroids and platelet transfusions during intrapartum period (average of 10 pint platelet transfusion). However for the IUD no obvious cause was identified. There were no gross anomalies. Fetal autopsy was not done.

Table 2: Mode of delivery and perinatal outcomes.

\begin{tabular}{|lllllll|}
\hline Mode of delivery & $\begin{array}{l}\text { Intra partum } \\
\text { transfusions }\end{array}$ & $\begin{array}{l}\text { Intra partum } \\
\text { findings }\end{array}$ & Apgar & B. wt & $\begin{array}{l}\text { NICU } \\
\text { stay }\end{array}$ & $\begin{array}{l}\text { Complications } \\
\text { Emergency LSCS }\end{array}$ \\
Nil & Grade III MSL & $6 / 10,7 / 10$ & $1.3 \mathrm{~kg}$ & Yes & Prematurity, IUGR \\
\hline FTVD & platelet & Nil & $8 / 10,9 / 10$ & $2.8 \mathrm{~kg}$ & No & Nil \\
\hline PTVD (IUD) & Nil & Spalding sign & $0 / 10,0 / 10$ & $640 \mathrm{gm}$ & No & Nil \\
\hline FTVD & 12 platelet & Nil & $8 / 10,8 / 10$ & $2.6 \mathrm{~kg}$ & Yes & Thrombocytopenia \\
\hline
\end{tabular}

LSCS: lower segment caesarean section, FTVD: full term vaginal delivery, PTVD: pre term vaginal delivery, MSL: meconium stained liquor, IUD: intra uterine demise, IUGR: intra uterine growth restriction.

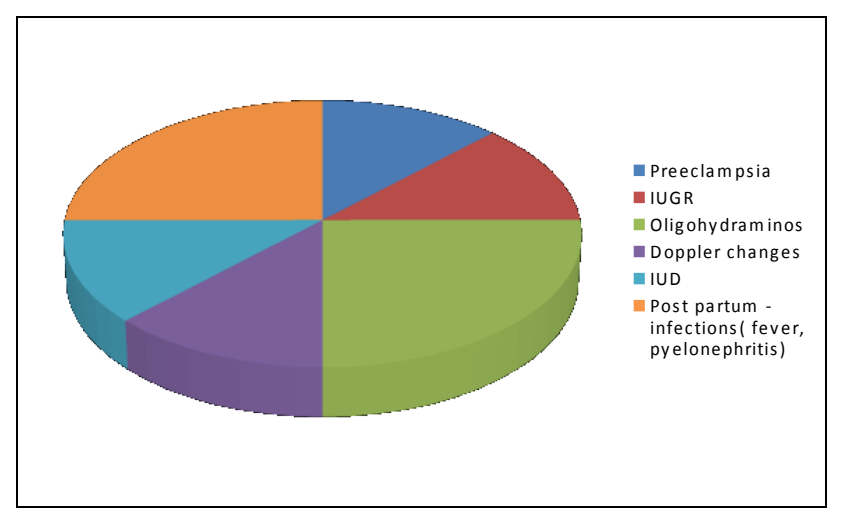

Figure 3: Antenatal and post natal complications.

One patient had grade II meconium stained liquor (MSL). Birth weights ranged from 1.3 to $2.8 \mathrm{~kg}$ with an average of $2.2 \mathrm{~kg}$. APGAR scores ranged from $6 / 10$ - 9/10 with a mean of 7.6. Two babies required neonatal intensive care unit (NICU) care. Neonatal complications included prematurity $(25 \%)$, IUGR $(25 \%)$, thrombocytopenia $(25 \%)$. One baby required pre term care. One baby had thrombocytopenia without any bleeding manifestations, resolved without transfusions Table 2.

\section{DISCUSSION}

\section{Evans syndrome is rare in pregnancy}

Complications in Evans syndrome in pregnancy can be divided into the consequences of autoimmune haemolytic anaemia and autoimmune thrombocytopenia. Pregnancy in association with autoimmune haemolytic anaemia may provoke life-threatening anaemia in $40-50 \%$ of cases, and stillbirth or severe postpartum haemolytic anaemia in 35$40 \%$ of infants. ${ }^{9}$ The major complication of autoimmune thrombocytopenia in pregnancy is maternal and fetal haemorrhage from thrombocytopenia. In a systematic review on Evans syndrome in pregnancy done by Lefklou, 3 out of 11 pregnancies were complicated by preeclampsia, one had abruption, and one had postpartum haemorrhage (PPH). 2 out of 11 had still births, one due to intra cranial subdural hematoma, second one due to erythroblastic feature with evidence of auto immune hemolysis. ${ }^{10}$ Whereas in our study 1 out of 4 patients had pre eclampsia, and none had abruption, PPH. There was one IUD, cause of which is unidentified. The fetus appears to be affected in some cases due to the transplacental passage of antibody causing hemolysis and still birth. ${ }^{11}$ Therefore monitoring for signs of fetal anemia has to be done. The additional use of intravenous gamma immunoglobulin may be helpful. It helps to block the ability of macrophages to remove platelets prematurely, and improve their survival time. Evidence suggests that maternal infusion of intravenous gamma immunoglobulin may prevent placental Fc-mediated endocytosis, thereby decreasing transplacental passage of maternally derived autoantibody. ${ }^{12}$

Autoimmune thrombocytopenia in pregnant women can cause moderate or severe thrombocytopenia in the fetus or newborn, irrespective of the mother's disease status. ${ }^{13}$ Platelet count in the previous sibling at birth can be a predictor of thrombocytopenia in subsequent pregnancy. The major risk of severe thrombocytopenia in newborns is intracranial haemorrhage, leading to death or neurological impairment. The frequency of intracranial haemorrhage is rare, estimated to be $1-3 \%$ of cases. Severe bleeding in the central nervous system and death ( $10 \%$ of cases) or neurological sequelae ( $20 \%$ of cases) has been reported. ${ }^{14}$

Concerns about teratogenic effects of the drugs used in the modern management of Evans add to the difficulties in the management during pregnancy. Treatment of choice includes steroids and intravenous immunoglobulins. Immunosuppressive drugs like rituximab, alemtuzumab are contraindicated in pregnancy. Splenectomy through open or laparoscopic approach is considered acceptable for patients with refractory Evans after second trimester pregnancy. ${ }^{15}$ Data from the literature about the mode of delivery do not support caesarean section except in obstetric indications. 
Use of vacuum, instrumental delivery, scalp electrodes are contra indicated. ${ }^{13}$

Evans syndrome in pregnancy is associated with good prognosis and usually responds to conventional treatment with steroids and IVIG. In contrast, the European survey of general population with Evans, which reported 54 cases, with median age of diagnosis 60 years, $22 \%$ patients died and $11 \%$ had uncontrolled disease. ${ }^{16}$ In children the mortality rate is as high as $7 \%$ and $2 / 3^{\text {rd }}$ have uncontrolled disease. ${ }^{17}$ According to The Confidential Enquiry into Maternal and Child Health (CEMACH) reports in United Kingdom there are no maternal deaths due to Evans syndrome in last 6 years. ${ }^{18}$ One more marked difference seen in pregnant cases compared with both adults and children is presence of neutropenia: neutropenia seen in $14-25 \%$ of children and adults, but not in pregnant women. It is not seen in pregnant women in our study also. This could be due to the overwhelming effect of neutrophilia occurring in pregnancy. ${ }^{10}$

\section{CONCLUSION}

Although rare in pregnancy Evans syndrome runs a benign course in pregnant women compared to non pregnant women. Neutropenia does not occur. There is good response to conventional treatment including steroids, IVIG, azathioprine and splenectomy for persistent cases. With appropriate treatment women with Evans can have successful pregnancies. Sometimes interestingly Evans syndrome resolves after delivery. Fetal outcome in few cases are less favourable due to transplacental passage of antibody. More detailed studies of Evans syndrome in pregnancy are required on fetal outcomes. Early detection, close surveillance and a multidisciplinary approach, is required to maximise the chance of a favourable outcome in women Evans syndrome.

Funding: No funding sources Conflict of interest: None declared

Ethical approval: The study was approved by the Institutional Ethics Committee

\section{REFERENCES}

1. Kaushansky K, Williams WJ. Williams hematology. New York: McGraw-Hill Medical; 2010.

2. Mackay I, Rose NR. The autoimmune diseases. Netherlands: Elsevier.; 2006.

3. Sasidharan PK, Bindya M, Kumar KG. Hematological manifestations of SLE at initial presentation: Is it underestimated? ISRN Hematol. 2012;2012:961872.
4. Font J, Jimenez S, Cervera R, Garcia-Carrasco M, Ramos-Casals M, Campdelacreu J, et al. Splenectomy for refractory Evan's syndrome associated with antiphospholipid antibodies: Report of two cases. Ann Rheum Dis. 2000;59(11):920-3.

5. Lavalle C, Hurtado R, Quezada JJ, Cabral A, Fraga A. Hemocytopenia as initial manifestation of systemic lupus erythematous. Prognostic significance. Clin Rheumatol. 1983;2(3):227-32.

6. Norton A, Roberts I, Management of Evans syndrome. Br J Haematol. 2006;132(2):125-37.

7. Rodeghiero F, Stasi R, Gernsheimer T, Michel M, Provan D, Arnold DM, et al. Standardization of terminology, definitions and outcome criteria in immune thrombocytopenic purpura of adults and children: report from an international working group. Blood. 2009;113(11):2386-93.

8. Buchanan GR, Adix L. Grading of hemorrhage in children with idiopathic thrombocytopenic purpura. J Pediatr. 2002;141(5):683-8.

9. Chaplin H, Cohen R, Bloomberg G, Kaplan HJ, Moore JA, Dorner I. Pregnancy and idiopathic autoimmune haemolytic anaemia: a prospective study during 6 months gestation and 3 months post-partum. $\mathrm{Br} \mathrm{J}$ Haematol. 1973;24:219-29.

10. Lefkou E, Nelson-Piercy C, Hunt BJ Eur J Obstet Gynecol Reprod Biol. 2010 Mar; 149(1):10-7.

11. Letts HW, Kredenster B. Thrombocytopenia, haemolytic anemia, and two pregnancies. Report of a case. Am J Clin Pathol. 1968;49(4):481-6.

12. Clark AL. Clinical uses of intravenous immunoglobulin in pregnancy. Clin Obstet Gynecol. 1999;42:368-80.

13. Gill KK, Kelton JG. Management of idiopathic thrombocytopenic purpura in pregnancy. Semin Hematol. 2000;37:275-89.

14. Kaplan C. Immune thrombocytopenia in the foetus and the newborn: diagnosis and therapy. Transfus Clin Biol. 2001;8:311-4.

15. Boren T, Reyes C, Montenegro R, Raimer K. A case of Evan's syndrome in pregnancy refractory to primary treatment options. J Matern Fetal Neonatal Med. 2007;20(11):843-5.

16. The spectrum of Evans syndrome in adults: new insight into the disease based on the analysis of 68 cases -Marc Michel, Vale'rie Chanet, Agne`s Dechartres, AnneSophie Morin, Jean-Charles Piette - Blood First Edition paper, July 28;2009.

17. Mathew P, Chen G, Wang W. Evans syndrome: results of national survey. J Pediatr Hematol Onco. 1997;19(5):433-7.

18. Lewis, G (ed). The Confidential Enquiry into Maternal and Child Health. Saving Mothers' Lives: reviewing maternal deaths to make motherhood safer;2007.

Cite this article as: Manjula SK, Arul Selvi JDT, Vishnu Priya KMN. Maternal and perinatal outcome of Evan's syndrome: a 5 years study in a tertiary care centre. Int J Reprod Contracept Obstet Gynecol 2019;8:2528-32. 